\title{
Phomopsis Stem Canker: A Reemerging Threat to Sunflower (Helianthus annuus) in the United States
}

\author{
Febina M. Mathew, Kholoud M. Alananbeh, James G. Jordahl, Scott M. Meyer, Lisa A. Castlebury, \\ Thomas J. Gulya, and Samuel G. Markell
}

First, second, third, fourth, and seventh authors: Department of Plant Pathology, North Dakota State University, Fargo 58102-6050; fifth author: United States Department of Agriculture-Agricultural Research Service (USDA-ARS) Systematic Mycology and Microbiology Lab, Beltsville, MD 20705; sixth author (retired): USDA-ARS Northern Crop Science Laboratory, Fargo, ND 58108.

Current address of F. M. Mathew: Department of Plant Science, South Dakota State University, Brookings, SD 57006.

Accepted for publication 9 March 2015.

\begin{abstract}
Mathew, F. M., Alananbeh, K. M., Jordahl, J. G., Meyer, S. M., Castlebury, L. A., Gulya, T. J., and Markell, S. G. 2015. Phomopsis stem canker: A reemerging threat to sunflower (Helianthus annuus) in the United States. Phytopathology 105:990-997.

Phomopsis stem canker causes yield reductions on sunflower (Helianthus annuиs L.) on several continents, including Australia, Europe, and North America. In the United States, Phomopsis stem canker incidence has increased 16-fold in the Northern Great Plains between 2001 and 2012. Although Diaporthe helianthi was assumed to be the sole causal agent in the United States, a newly described species, D. gulyae, was found to be the

Great Plains, 275 infected stems were collected between 2010 and 2012. Phylogenetic analyses of sequences of the ribosomal DNA internal transcribed spacer region, elongation factor subunit $1-\alpha$, and actin gene regions of representative isolates, in comparison with those of type specimens, confirmed two species (D. helianthi and D. gulyae) in the United States. Differences in aggressiveness between the two species were determined using the stem-wound method in the greenhouse; overall, $D$. helianthi and $D$. gulyae did not vary significantly $(P \leq 0.05)$ in their aggressiveness at 10 and 14 days after inoculation. These findings indicate that both Diaporthe spp. have emerged as sunflower pathogens in the United States, and have implications on the management of this disease.
\end{abstract} primary cause of Phomopsis stem canker in Australia. To determine the identity of Diaporthe spp. causing Phomopsis stem canker in the Northern

Phomopsis stem canker is widespread in many sunflower (Helianthus annuus L.) regions in the world (Gulya et al. 1997; Masirevic and Gulya 1992; Thompson et al. 2011). The disease has been one of the primary limiting factors for sunflower production in Europe, where yield losses up to $50 \%$ and losses in oil content in excess of $10 \%$ have occurred (Laville 1986; Masirevic and Gulya 1992). According to data from the annual Sunflower Crop Survey coordinated by the U.S. National Sunflower Association (Mandan, ND), incidence of fields with Phomopsis stem canker has increased from approximately $1.5 \%$ of the U.S. crop in 2001 to $24.4 \%$ in 2012 (Kandel 2012). Historically, yield and oil losses due to Phomopsis stem canker in the United States have been minimal (Kandel 2012). However, in 2010, a Phomopsis stem canker epidemic occurred on sunflower in the Northern Great Plains, with incidence highest in North Dakota, South Dakota, and Minnesota, where over $75 \%$ of the U.S. sunflower crop is grown. Several isolated fields in North Dakota and Minnesota had an incidence of over $50 \%$ of the plants infected and estimated yield losses up to $40 \%$. It was unclear what triggered the sudden reemergence of Phomopsis stem canker in 2010, given that the disease was first recorded in North Dakota and Minnesota in 1984 (Hajdu et al. 1984). In response to the epidemic, the National Sunflower Association declared the development of management tools for Phomopsis stem canker one of their top research priorities (http://sunflowernsa.com).

Corresponding author: S. G. Markell; samuel.markell@ndsu.edu

*The $\boldsymbol{e}$-Xtra logo stands for "electronic extra" and indicates that two supplementary figures and one supplementary table are published online.

http://dx.doi.org/10.1094/PHYTO-11-14-0336-FI

(C) 2015 The American Phytopathological Society
Additional keyword: pathogenicity.

The pathogen causing Phomopsis stem canker on sunflower was first described as Diaporthe helianthi Munt.-Cvetk., Mihaljč. \& M. Petrov (anamorph Phomopsis helianthi Munt.-Cvetk., Mihaljč. \& M. Petrov (Muntañola-Cvetković et al. 1985) in the former Yugoslavia in 1980. Although D. helianthi was described as the causal agent (Aćimović and Štraser 1982; Muntañola-Cvetković et al. 1985), the possibility of multiple species infecting sunflower was raised by the researchers in the early 1980s (MuntañolaCvetković et al. 1985). However, there was little evidence to support the multiple-species hypothesis. At that time, host association was used for identification of Diaporthe spp., because morphological and culture characteristics are inadequate or unreliable for species differentiation (van Rensburg et al. 2006). Consequently, all Diaporthe spp. isolated from infected sunflower were assumed to be caused by $D$. helianthi. However, there appeared to be distinct biological differences between $D$. helianthi isolates causing disease on sunflower in Europe and those causing disease on sunflower in the United States (Gulya et al. 1997). The U.S. isolates readily produced perithecia in culture but European isolates did not. Despite some evidence of biological differences among the Diaporthe isolates and a hypothesis suggesting that multiple species were involved, disease symptoms associated with the pathogen on sunflower were thought to be the same everywhere. Additionally, it was reported by Herr et al. (1983) that the severity of symptoms expressed in the commercial sunflower hybrids inoculated with the same isolate varied from plant to plant, further complicating phenotyping. The molecular evidence provided more recently strongly supports the hypothesis that multiple Diaporthe spp. can cause Phomopsis stem canker on sunflower (Thompson et al. 2011). Three Diaporthe spp. (D. gulyae R. G. Shivas, S. M. Thomps. \& A. J. Young; D. kongii R. G. Shivas, S. M. Thomps. \& A. J. Young; and D. kochmanii R. G. Shivas, S. M. Thomps. \& 
A. J. Young) were responsible for the disease outbreaks in Australia in 2009 (Thompson et al. 2011), where D. helianthi has not been identified and remains a biosecurity threat.

When multiple pathogenic species cause the same disease, it is important to determine whether there are differences in aggressiveness among them, particularly as it relates to breeding for plant resistance. The term "aggressiveness", as used in this article, is based on the quantitative variation of pathogenicity on susceptible hosts (Pariaud et al. 2009). Variation in aggressiveness among $D$. helianthi isolates has been reported on sunflower (Encheva and Kiryakov 2002). Herr et al. (1983) examined the reaction of commercial sunflower hybrids inoculated with $15 \mathrm{D}$. helianthi isolates and observed variation in aggressiveness characteristics among the isolates, such as differences in lesion size and infectious period. Additionally, it was reported by Herr et al. (1983) that the severity of symptoms expressed in commercial sunflower hybrids varied from plant to plant when they were inoculated with the same D. helianthi isolate, complicating phenotyping. Among the D. gulyae isolates, variation in symptoms and lesion size that these produce was reported on sunflower by Thompson et al. (2011). Says-Lesage et al. (2002) further showed that extensive genetic differences occur among $D$. helianthi strains from different geographical origins; therefore, it is likely that there may be genetic variability between the populations of $D$. helianthi and D. gulyae occurring in the United States and in other sunflower production regions of the world, making evaluation of local populations critical for disease management. Although $D$. helianthi has caused significant yield losses in Europe (Masirevic and Gulya 1992) and D. gulyae has caused severe Phomopsis stem canker epidemics in Australia (Thompson et al. 2011), a direct comparison of aggressiveness of $D$. gulyae and D. helianthi has not been done.

The specific objectives of this study were to (i) phylogenetically characterize isolates of Diaporthe from sunflower causing Phomopsis stem canker in the Northern Great Plains and (ii) examine the aggressiveness of the Diaporthe isolates from sunflower. Among the major findings of this study, we have determined that at least two distinct Diaporthe spp. have emerged as sunflower pathogens in the United States.

\section{MATERIALS AND METHODS}

Survey collection and identification of Diaporthe isolates. A survey of sunflower fields was conducted in the Northern Great Plains states of Minnesota, North Dakota, and South Dakota from 2010 to 2012 in an effort to identify sunflower stem pathogens. In 2010, 55 sunflower fields were selected arbitrarily, with no fields closer than $5 \mathrm{~km}$ from a previously selected field. In each field, one to two 10-m-long transects (rows) were randomly selected for survey and collection. Two to three sunflower stalks exhibiting a variety of stem symptoms (wilting, lodging, and lesions of varying size and color) were arbitrarily collected in each transect.
In 2011 and 2012, the survey and collection of stem pathogens specifically targeted Phomopsis stem canker. In all, 51 and 26 fields with Phomopsis stem canker were arbitrarily selected in 2011 and 2012, respectively, and two to three diseased stalks (Supplementary Figs. 1 and 2) were collected along one to two 10-m-long transects in each field. In total, 234 isolates (83 isolations in 2010, 96 in 2011, and 55 in 2012) were recovered from 275 stalks collected (Table 1).

Stem samples were washed with tap water for $2 \mathrm{~min}$, and $1-\mathrm{cm}-$ long pieces were cut from infected tissue. The pieces were surface sterilized in sodium hypochlorite $(10 \%)$ and ethanol $(70 \%)$ for $1 \mathrm{~min}$ each, rinsed in sterile distilled water four times, and blotted between sterile filter papers. Four pieces were placed on potato dextrose agar (PDA; Difco Laboratories, Detroit) amended with $0.02 \%$ streptomycin sulfate (Sigma-Aldrich, St. Louis) to avoid bacterial growth. Plates were incubated at room temperature for 7 to 14 days under alternating light and dark conditions (12 h each). Cultures were scored for presence or absence of different fungi, including Diaporthe spp., based on morphology (Barnett and Hunter 1972). After 14 days, Diaporthe isolates were purified by transferring hyphal tips to fresh plates of PDA amended with $0.02 \%$ streptomycin sulfate.

DNA of 234 isolates collected during the 3-year survey was extracted from lyophilized mycelium scraped from the surface of 7 -day-old cultures growing on PDA and resuspended in $50 \mu \mathrm{l}$ of rehydration solution (1\% Tris-EDTA buffer) using a Wizard Genomic DNA Purification Kit (Promega Corp., Madison, WI). A 5- $\mu$ l aliquot of each DNA sample was electrophoresed on a $1 \%$ agarose gel to confirm quality. DNA was also quantified with a NanoDrop spectrophotometer (NanoDrop Technologies, Wilmington, DE). The 234 Diaporthe isolates were preliminarily identified to species by amplifying and sequencing the internal transcribed spacer (ITS) regions using primers ITS5 and ITS4 (White et al. 1990). Cycle parameters included an initial denaturation at $94^{\circ} \mathrm{C}$ for $3 \mathrm{~min}$; followed by 30 cycles of denaturation at $94^{\circ} \mathrm{C}$ for $1 \mathrm{~min}$, annealing at $55^{\circ} \mathrm{C}$ for $1 \mathrm{~min}$, and extension at $72^{\circ} \mathrm{C}$ for $1 \mathrm{~min}$; and a final extension at $72^{\circ} \mathrm{C}$ for $10 \mathrm{~min}$ (White et al. 1990). A 5- $\mu \mathrm{l}$ aliquot of each polymerase chain reaction (PCR) product was run electrophoretically on a $1 \%$ agarose gel to confirm amplification. All DNA samples were sequenced (McLab, San Francisco and GenScript USA Inc., Piscataway, NJ) using the respective PCR primers. Forward and reverse sequences were edited, and the contigs were aligned using Bioedit (Hall 1999). Analysis of the edited sequences was performed using the Basic Local Alignment Search Tool (BLASTN) at the GenBank nucleotide database (National Center for Biotechnology Information [NCBI]). The corresponding fungi were identified based on top BLAST results (lowest e-value, highest score, and greatest similarity). The DNA sequences from isolates that were found to have more than $95 \%$ identity with Diaporthe sequences in GenBank, and also to have an e-value less than e-10 in the BLASTN searches, were used for further analysis.

To establish a well-resolved phylogeny and to further clarify the phylogenetic position of Diaporthe spp. infecting sunflower in the

TABLE 1. Number of fields surveyed, stems collected, and Diaporthe isolates recovered in the Northern Great Plains in 2010, 2011, and 2012

\begin{tabular}{|c|c|c|c|c|c|c|c|}
\hline \multirow[b]{2}{*}{ Year } & \multirow[b]{2}{*}{ State $^{\mathrm{a}}$} & \multirow[b]{2}{*}{ Fields Surveyed } & \multirow[b]{2}{*}{ Total number of stems collected } & \multicolumn{4}{|c|}{ Number and percentage of Diaporthe isolates recovered } \\
\hline & & & & D. helianthi & D. helianthi isolation (\%) & D. gulyae & D. gulyae isolation (\%) \\
\hline 2010 & $\mathrm{MN}$ & 1 & 6 & 4 & 66.7 & 0 & 0.0 \\
\hline 2010 & ND & 6 & 8 & 7 & 87.5 & 0 & 0.0 \\
\hline 2011 & MN & 14 & 37 & 27 & 73.0 & 0 & 0.0 \\
\hline 2011 & ND & 14 & 23 & 8 & 34.8 & 0 & 0.0 \\
\hline 2011 & SD & 23 & 70 & 59 & 84.3 & 2 & 2.9 \\
\hline 2012 & SD & 11 & 15 & 15 & 100.0 & 0 & 0.0 \\
\hline
\end{tabular}

${ }^{\mathrm{a}} \mathrm{MN}=$ Minnesota, $\mathrm{ND}=$ North Dakota, and SD = South Dakota. 
Northern Great Plains, 19 representative Diaporthe isolates were selected and characterized by phylogenetic analyses of two gene fragments, including translation elongation factor 1-alpha (EF1- $\alpha)$ and actin (ACT) (Table 2). An intron region of the EF1- $\alpha$ gene was amplified using primers EF1-728F and EF1-986R (Carbone and Kohn 1999). A region of the ACT gene spanning an intron was amplified using the primers ACT-512F and ACT-783R (Carbone and Kohn 1999). Reactions for all PCR amplifications were performed in a $25-\mu 1$ mixture containing template DNA at 20 to $30 \mathrm{ng} /$ reaction, $10 \mu \mathrm{M}$ each primer, $10 \mathrm{mM}$ each dNTP, Taq DNA Polymerase (Qiagen, Valencia, CA) at 5 units/ $\mu$ l, and 10× Qiagen PCR Buffer containing $15 \mathrm{mM} \mathrm{MgCl}_{2}$ (Qiagen). The PCR cycling protocols were denaturation at $94^{\circ} \mathrm{C}$ for $5 \mathrm{~min}$; followed by 39 cycles of $30 \mathrm{~s}$ at $95^{\circ} \mathrm{C}, 50 \mathrm{~s}$ at $55^{\circ} \mathrm{C}$ (for primer pairs ACT-512F/ ACT-783R) or $58^{\circ} \mathrm{C}$ (for primers pairs EF1-728F/EF1-986R), and $1 \mathrm{~min}$ at $72^{\circ} \mathrm{C}$; and a final step of $10 \mathrm{~min}$ at $72^{\circ} \mathrm{C}$ (Carbone and Kohn 1999). A 5- $\mu$ l aliquot of each PCR product was electrophoresed on a $1 \%$ agarose gel to confirm amplification. All DNA samples were sequenced (McLab and GenScript USA Inc.) using the respective PCR primers. The DNA sequences that were sequenced and analyzed in this study were deposited in GenBank under accession numbers KM230818 to KM230869 and KM230901 to KM230926 (Table 2).

Molecular phylogenetics. The ITS, EF1- $\alpha$, and ACT sequences of Diaporthe isolates were aligned using the default parameters of ClustalX (Thompson et al. 1997) and adjusted manually by visual examination using the Molecular Evolutionary Genetics Analysis (MEGA) software v5.2.2 (Tamura et al. 2011) prior to being exported as NEXUS files for subsequent analyses. Prior to the combined analyses, the concordance of the three gene datasets was evaluated with the partition-homogeneity test (Farris et al. 1994) implemented with PAUP* v4.0b10 (Sinauer Associates, Inc., Sunderland, MA) (Swofford 2002), using 1,000 random repartitions (Felsenstein 1985), with MAXTREES set to 5,000. The null hypothesis of congruence was rejected if $P<0.001$ (Darlu and Lecointre 2002; Dettman et al. 2003). For the combined dataset, sequences were concatenated using Mesquite v2.75 (Maddison and Maddison 2011).

Phylogenies based on maximum parsimony (MP) were inferred using MEGA, and Bayesian inference (BI) using MrBayes v3.1.2 (Ronquist and Huelsenbeck 2003), under the estimated model of evolution. For the MP analyses, heuristic searches for the most parsimonious trees were conducted using the tree bisectionregrafting algorithm (Nei and Kumar 2000) with search level 1, in which the initial trees were obtained by random addition (10 replicates). For the MP analyses, gaps were treated as missing data and relative support for branches was estimated with 1,000 bootstrap replications (Felsenstein 1985).

For BI analyses, two simultaneous runs were conducted with Markov chain Monte Carlo (MCMC) chains with default priors and a conservative burn-in of $25 \%$ and tree sampling every 100 generations. Four parallel MCMC chains were run for 1,000,000 generations; a burn-in of 2,500 generations was found to be sufficient to achieve stationary model parameters using Tracer v1.4.1 (Rambaut and Drummond 2007). Within each run, the average standard deviation of split frequencies and the potential scale reduction factor statistics from MrBayes were used to evaluate topological and branch-length convergence, respectively.

The best-fitting evolutionary models for the Bayesian analyses were estimated using ModelTest v3.7 (Posada and Crandall 1998) by Akaike information criterion (Akaike 1974). For the ITS region, the general time-reversible model with a proportion of invariant sites $(+\mathrm{I})$ and a six-category, discrete $\gamma(+\mathrm{G})$ shape distribution (Lanave et al. 1984) was selected as the best fitting model. Sequences for the outgroup taxa Valsa ceratosperma (Tode) Maire (NCBI accession number AY347335) and Leucostoma persoonii (Nitschke) Höhn. (NCBI accession number DQ996042) were obtained from GenBank. For the combined EF1- $\alpha$ and ACT gene phylogenetic analyses, the best-fitting model of nucleotide substitution was the HKY+G (Yang 1994). The outgroup Chrysoporthella hodgesiana Gryzenhout and M. J. (isolate CMW9995) was obtained from GenBank (NCBI accession number GQ290152 for C. hodgesiana $\mathrm{EF} 1-\alpha$ sequence and GQ290170 for ACT sequence). The 49 sequences in the combined data set (including the outgroup C. hodgesiana) comprised $667 \mathrm{bp}$ of aligned sequence. The Bayesian posterior probabilities (PP) for each node were estimated from the resulting $50 \%$ majority-rule consensus tree and nodes with $95 \%$ or greater PP were considered significant (Wilcox et al. 2002). Each of the Bayesian MCMC analyses was run at least twice to confirm the consistency of the results. Phylogenetic trees inferred using MrBayes analyses were observed in FigTree v1.3.1 (Rambaut 2009).

Aggressiveness of Diaporthe spp. on sunflower. To compare aggressiveness between Diaporthe spp. and also among

TABLE 2. Isolates used in this study, the genes sequenced, and GenBank accessions

\begin{tabular}{|c|c|c|c|c|c|c|}
\hline \multirow[b]{2}{*}{ Isolates $^{\mathrm{a}}$} & \multirow[b]{2}{*}{ Year of isolation } & \multirow[b]{2}{*}{ State $^{\mathrm{b}}$} & \multirow[b]{2}{*}{ Species identity $^{\mathrm{C}}$} & \multicolumn{3}{|c|}{ GenBank accession numbers } \\
\hline & & & & ITS & $E F 1-\alpha$ & $\mathrm{ACT}$ \\
\hline D6 & 2010 & SD & Diaporthe gulyae & KM230818 & KM230844 & KM230901 \\
\hline D9 & 2010 & SD & D. gulyae & KM230819 & KM230845 & KM230902 \\
\hline D14 & 2010 & SD & D. gulyae & KM230821 & KM230847 & KM230904 \\
\hline D21 & 2010 & SD & D. gulyae & KM230822 & KM230848 & KM230905 \\
\hline D32 & 2010 & SD & D. gulyae & KM230823 & KM230849 & KM230906 \\
\hline R_P132 & 2011 & MN & D. helianthi & KM230834 & KM230860 & KM230917 \\
\hline R_P126 & 2011 & MN & D. helianthi & KM230835 & KM230861 & KM230918 \\
\hline R_P121 & 2011 & MN & D. helianthi & KM230836 & KM230862 & KM230919 \\
\hline R_P105 & 2011 & $\mathrm{MN}$ & D. helianthi & KM230837 & KM230863 & KM230920 \\
\hline R_P140 & 2011 & MN & D. helianthi & KM230838 & KM230864 & KM230921 \\
\hline R_P137 & 2011 & $\mathrm{MN}$ & D. helianthi & KM230839 & KM230865 & KM230922 \\
\hline
\end{tabular}

${ }^{a}$ Isolates are a subset of 234 Diaporthe isolates and were chosen as representatives for species-level identification.

b $\mathrm{SD}=$ South Dakota, MN = Minnesota, and ND = North Dakota.

${ }^{c}$ Species identity was established based on phylogenetic analysis of the internal transcribed spacer region (ITS), elongation factor subunit 1- $\alpha$ (EF1- $\alpha$ ), and actin (ACT). 
isolates within the two species, 10 isolates each of $D$. helianthi and D. gulyae were selected as representative of each species. These isolates included 10 of $D$. gulyae from South Dakota, 8 of $D$. helianthi from Minnesota, 1 of $D$. helianthi from North Dakota, and 1 of $D$. helianthi from South Dakota. Isolates of Diaporthe spp. were cultured on PDA amended with $0.02 \%$ streptomycin sulfate to avoid bacterial growth. Plates were incubated at room temperature for 10 days under 12-h cycles of light and darkness. Mycelial plugs ( $4 \mathrm{~mm}$ in diameter) were taken from the margin of the growing colony.

The United States Department of Agriculture (USDA) confection inbred line 'HA 288' is considered universally susceptible to D. helianthi, and was selected as the host genotype for the study. Two seeds were planted in moist planting mix (Sunshine Mix number 1; Sun Grow Horticulture Products, Belleview, WA) in 7.5-liter circular plastic pots. The pots were placed in a greenhouse with a temperature of 22 to $25^{\circ} \mathrm{C}$ and a 16-h cycle of light and darkness, and were watered on alternate days. Based on the results of an experiment to determine the most effective inoculation method of Diaporthe spp. on sunflower (data not published), the stem-wound method was selected to compare aggressiveness. When the plants were between the V4 and V6 growth stages (four to six true leaves), the stems were wounded with a micropipette tip $(100 \mu \mathrm{l})$ on the second internode and a Diaporthe-infested mycelial plug was placed on the wound. A sterile PDA plug was placed on the wound of the nontreated control. After inoculation, the plants were returned to the same greenhouse conditions. Disease severity was evaluated at 3, 10, and 14 days after inoculation using a 0 -to-5 scale modified from Thompson et al. (2011), where $0=$ no discoloration; $1=$ low level discoloration at site of inoculation; $2=$ slight discoloration or lesion 1 to $2 \mathrm{~mm}$ in length; $3=$ necrotic lesions 2 to $5 \mathrm{~mm}$ in length, some colored stem streaking, leaf wilting, and twisting; $4=$ lesions 5 to $10 \mathrm{~mm}$ in length, significant necrosis and dark-colored stem streaking, leaf and plant wilting, twisting, stunting, and some lodging; and $5=$ lesions exceeding $10 \mathrm{~mm}$ in length, severe leaf necrosis, lodging, or plant death.

The trial was conducted in a completely randomized design with 12 plants evaluated per treatment, and the experiment was repeated twice. The experimental unit was the single plant in each pot and each treatment was replicated 12 times (12 plants). Analysis of data based on observed ranks was performed in SAS. The ordinal data from the disease rating scale did not have a normal distribution; therefore, they were analyzed using the nonparametric procedure of Brunner et al. (2002) as described by Shah and Madden (2004). Preliminary data analysis showed that the results of both experimental runs were very similar; therefore, the data from both runs were combined for the final analysis. A repeated-measures analysis was used to identify significant effects of time on the disease produced by the two Diaporthe spp. and isolates within species. The overall and interaction effect of Diaporthe spp., isolates within species, and time on disease severity was determined by the ATS of ranked data. The PROC RANK procedure in SAS was used to obtain the mean treatment rank (R) followed by PROC MIXED to generate relative effects (RE). According to Shah and Madden (2004) and Akritas (1991), the mean treatment rank (R) for the $i$ th treatment is defined by the equation $\mathrm{R}=\frac{1}{n}\left(\sum(k-1) \hat{n}\right) \mathrm{R}_{\mathrm{i}}$, where $\mathrm{R}_{\mathrm{i}}$ is the rank among all $N$ observations and $n_{\mathrm{i}}$ indicates independent experimental units or replications $\left(\mathrm{k}=1, \ldots, n_{\mathrm{i}}\right)$ per treatment. RE, defined by means of probabilities derived from the marginal distribution functions of disease severity, are generated by the equation $\mathrm{RE}=(\mathrm{R}-0.5) / N$, where $\mathrm{R}$ is the mean treatment rank and $N$ is the total number of observations in the data analysis. Confidence intervals were calculated using LD_CI macro in SAS at $P \leq 0.05$ (Brunner et al. 2002).

In addition to comparing aggressiveness of the two Diaporthe spp. and isolates within the two species, the experiment was also used to complete Koch's postulates of D. gulyae, which was not previously reported as a pathogen of sunflower causing Phomopsis stem canker in the United States.

\section{RESULTS}

Survey collection and identification of Diaporthe isolates. During the 3-year survey, two species of Diaporthe were isolated from infected sunflower stems collected from the Northern Great Plains (Table 1). The frequency of D. helianthi and D. gulyae varied among the 3 years and among the three states. In 2010, D. helianthi was isolated at frequencies of $3.9 \%$ from samples collected in South Dakota, $66.7 \%$ from samples collected in Minnesota, and $87.5 \%$ from samples collected in North Dakota. However, D. gulyae was isolated at a frequency of $90.8 \%$ from samples collected in South Dakota (Table 1). In 2011, D. helianthi was isolated at a frequency of $73.0 \%$ from samples collected in Minnesota, 34.8\% North Dakota, and 84.3\% in South Dakota, whereas D. gulyae was isolated at frequency of $2.9 \%$ from samples collected in South Dakota (Table 1). In 2012, only D. helianthi was isolated (Table 1).

An approximately 600-bp region of the ITS gene region was amplified from 234 isolates originating from the United States, and was used to query the GenBank database directly. A BLASTN search of GenBank was performed for the ITS sequences of 163 U.S. isolates identified as $D$. helianthi based on comparison with the type isolate from sunflower $(D$. helianthi strain CBS 592.81, accession number AY705842) as designated by MuntañolaCvetković et al. (1985) (Table 2). These isolates differed at a single nucleotide site from the type isolate for the ITS gene. A BLASTN search of GenBank was performed for the ITS sequences of the D. gulyae U.S. isolates (72 isolates, $30.4 \%$ ), which showed that the best match was Phomopsis sp. AJY-2011a strain T12505G (D. gulyae, accession number JF431299) from $H$. annuus in Australia, with identities $=540 / 540(100 \%)$ and gaps $=0 / 540(0 \%)$ (Table 2).

Molecular phylogenetics. For sequences of the 19 Diaporthe isolates selected as representative of the U.S. population, Bayesian and MP analyses produced similar topologies in analyses of each locus alone (ITS) and combined (EF1- $\alpha$ and ACT). In the ITS tree, of the 19 Diaporthe isolates, 12 isolates clustered with the ex-type culture of $D$. helianthi (CBS 592.81, accession number AY705842) and 7 isolates with the ex-type culture of Phomopsis sp. AJY-2011a strain T12505G (D. gulyae, MycoBank MB561569, accession number JF431299) in phylogenetic analyses of the ITS data set (data not shown). The $D$. helianthi isolates from the Northern Great Plains clustered $(\mathrm{PP}=90 \%)$ with the $D$. helianthi isolates from $H$. annuus in Croatia, France, Yugoslavia, and the United States in the ITS tree. In contrast, D. gulyae collections from the Northern Great Plains were placed in the group containing D. gulyae isolates from $H$. annuus in Australia as well as the type sequences of D. ambigua, D. angelicae, D. stewartii, D. dauci, D. longicolla, and $D$. phaseolorum. The D. gulyae clade appears as a moderately wellsupported branch, with $70 \%$ PP in the ITS tree, compared with $100 \%$ PP for the well-established D. helianthi clade (data not shown). Because the ITS tree was not well resolved for Bayesian and MP analyses and it gave no additional information not already addressed by the BLAST search, the ITS tree was not included in this article.

For further characterization of the Diaporthe isolates using combined genes, EF1- $\alpha$ and ACT genes were combined based on the results of the partition-homogeneity test $(P=0.433)$ indicating that the trees reflect the same underlying phylogeny. The MP analysis for the combined tree resulted in one most parsimonious tree (length $=269$, consistency index $[\mathrm{CI}]=0.788$, retention index $[\mathrm{RI}]=0.965$, and rescaled consistency index $[\mathrm{RCI}]=0.789$ ) for all sites and parsimony-informative sites (Fig. 1). Overall, there was an increase in bootstrap support in the resulting phylogenetic tree when the combined dataset was used (Fig. 1). Whereas D. gulyae formed 
a monophyletic group with the type strains DG54025 and DG54026 $(\mathrm{PP}=100 \%), D$. helianthi isolates clustered together with the type strain CBS 592.81 and was supported by an overall of PP of $100 \%$ (Fig. 1).

Aggressiveness of Diaporthe spp. The disease symptoms caused by the two Diaporthe spp. were evaluated at 3,10, and 14 days after inoculation using RE and their 95\% CI. Test statistics indicated no significant effect of experiment or interaction effects between experiment and Diaporthe spp. in the overall development of Phomopsis stem canker on sunflower. The repeated-measures analysis identified a significant interaction between Diaporthe spp. and time at $P=0.0009$. The interaction was because $D$. gulyae and $D$. helianthi differed in their RE at 3 days after inoculation (Table 3 ). However, there were no significant differences in RE between the two Diaporthe spp. at 10 and 14 days after inoculation (Fig. 2;
Table 3). Based on visual symptoms, D. gulyae caused brown lesions extending upward from the inoculation site, wilting of stem and leaves at the node closest to the site of inoculation 3 days after inoculation, and plant death. In contrast, $D$. helianthi caused tan to brown elongated lesions 10 days after inoculation and no plant death was observed. No symptoms were observed in the control plants.

The repeated-measures analysis also identified a significant interaction among Diaporthe isolates (within the two species) and time at $P<0.0001$. Among $D$. gulyae isolates, significant differences in their RE was more evident at 3 days after inoculation compared with 10 and 14 days after inoculation (Supplementary Table S1). In contrast, among D. helianthi isolates, significant differences in their RE were evident at 3 and 10 days after inoculation compared with 14 days after inoculation. For example,

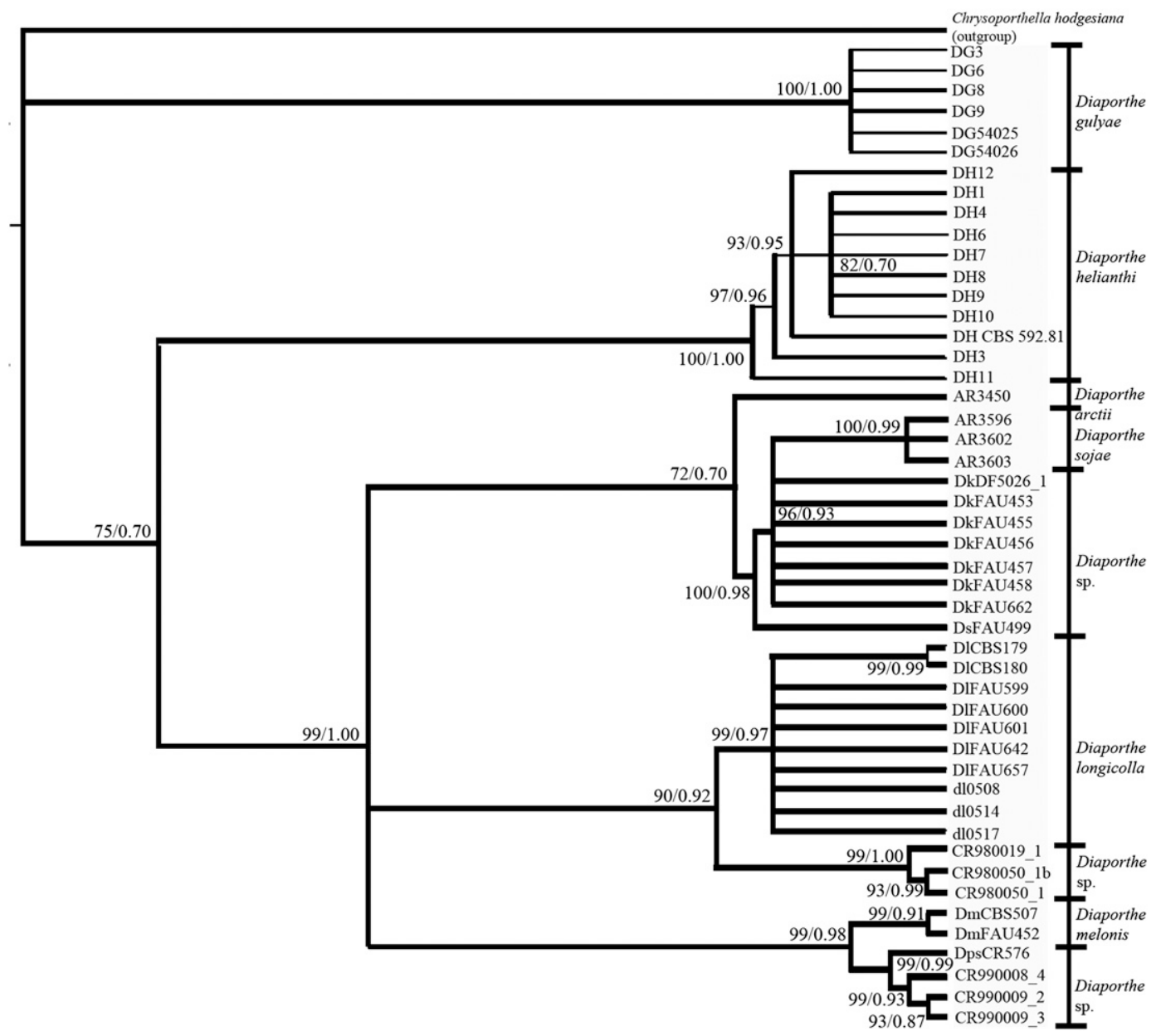

Fig. 1. Phylogenetic tree resulting from the alignment of 667 characters of the combined EF1- $\alpha$ and ACT gene region using the Bayesian inference and maximum parsimony analyses of the Diaporthe isolates from sunflower. Branch labels represent bootstrap support values from maximum parsimony analyses $(\geq 70)$ over Bayesian posterior probability values $(\geq 0.70)$. Diaporthe isolates recovered from sunflower fields in the Northern Great Plains have labels 'DH' for Diaporthe helianthi (CBS $592.81=$ type strain) and 'DG' for Diaporthe gulyae (DG54025 and DG54026 = type strains). Chrysoporthella hodgesiana (isolate CMW9995) was used as the outgroup (National Center for Biotechnology Information accession number GQ290152 for EF1- $\alpha$ sequence and GQ290170 for ACT sequence).

TABLE 3. Median, mean rank and relative treatment effects for Phomopsis stem canker severity rating caused by two Diaporthe spp. on sunflower at 3 , 10, and 14 days after inoculation

\begin{tabular}{|c|c|c|c|c|c|c|c|c|c|}
\hline \multirow[b]{3}{*}{ Species } & \multicolumn{9}{|c|}{ Days after inoculation } \\
\hline & \multicolumn{3}{|c|}{ Median disease rating ${ }^{\mathrm{a}}$} & \multicolumn{3}{|c|}{ Mean rank } & \multicolumn{3}{|c|}{ Estimated relative effect ${ }^{b}$} \\
\hline & 3 & 10 & $\overline{14}$ & 3 & 10 & 14 & 3 & 10 & 14 \\
\hline Diaporthe gulyae & 2.5 & 3.0 & 4.0 & 257.9 & 378.5 & 495.0 & $0.36(0.32,0.39)$ & $0.53(0.49,0.56)$ & $0.69(0.66,0.71)$ \\
\hline D. helianthi & 2.0 & 3.0 & 3.0 & 194.2 & 370.2 & 370.2 & $0.27(0.24,0.30)$ & $0.51(0.47,0.56)$ & $0.65(0.62,0.67)$ \\
\hline
\end{tabular}

${ }^{a}$ Disease severity ratings were evaluated at 3,10, and 14 days after inoculation using a 0-to-5 scale modified from Thompson et al. (2011).

b Relative treatment effects were calculated using the nonparametric method for ordinal data described by Shah and Madden (2004). 
the RE of DH10 was lower than that of DH7, DH8, and DH9 at 3 and 10 days after inoculation; however, the RE of the four $D$. helianthi isolates were not significantly different in their RE at 14 days after inoculation.

To complete Koch's postulates, D. gulyae was reisolated from the inoculated HA 288 stems 14 days after inoculation and the identity of the pathogen was confirmed via sequencing of the ITS regions using primers ITS5 and ITS4 (White et al. 1990). The pathogen was not isolated from the control plants.

\section{DISCUSSION}

The results of this study demonstrated that two Diaporthe spp. (D. helianthi and D. gulyae) are responsible for Phomopsis stem canker on sunflower in the United States. The identification of Diaporthe spp. causing Phomopsis stem canker was based on DNA sequence analyses of the ITS, EF- $1 \alpha$, and ACT genes because morphological characteristics are unreliable (van Rensburg et al. 2006). Phylogenetic analysis of ITS sequences of D. helianthi isolates from the United States represent a tight monophyletic clade and revealed that they were closely related to all isolates from France and the former Yugoslavia, where yield losses up to 40 and $50 \%$, respectively, due to Phomopsis stem canker have been reported (Carré 1993; Pentericci 1988; Rekab et al. 2004). In contrast, D. gulyae isolates from the United States appeared as a moderately well-supported clade based on ITS sequences (data not shown). The consensus BI tree and MP tree topology inferred from the combined dataset identified two independent clusters for $D$. helianthi and D. gulyae supported by higher measures of clade support of 100 and $88 \%$ PP, respectively (Fig. 1). When the aggressiveness of the two Diaporthe spp. was compared in greenhouse conditions, D. gulyae produced symptoms consistent with Phomopsis stem canker more quickly than D. helianthi; however, both were equally damaging pathogens over time. To the best of our knowledge, this is the first report of D. gulyae causing Phomopsis stem canker on sunflower in the United States, and its identification may affect the development and deployment of management tools for the disease.

The existence of two Diaporthe spp. on sunflower in the United States could be explained by several hypotheses. Because D. helianthi and D. gulyae can be transmitted through seed (Herr et al. 1983; Thompson et al. 2011), one hypothesis would suggest a recent introduction of new species on seed. D. helianthi was confirmed by morphology in Ohio in 1980 (Herr et al. 1983), followed by Texas in 1982 (Yang et al. 1984) and Minnesota and North Dakota in 1984 (Hajdu et al. 1984). Although we did not have any Diaporthe isolates from sunflower prior to 2010 for use in our molecular study, we were able to perform Bayesian analyses of the ITS sequences deposited by Miric (2002) in the GenBank nucleotide database of the two isolates (from North Dakota) collected in 1984 and 1988 (data not presented). The isolates were identified as $D$. helianthi based on comparison with the type isolate strain CBS 592.81 (accession number AY705842). Although this eliminates the hypothesis of a recent introduction of $D$. helianthi into the United States, we did not confirm the same for D. gulyae.

Another hypothesis is that both Diaporthe spp. were endemic in the United States. Herr et al. (1983) reported that Diaporthe isolates identified causing Phomopsis stem canker in Ohio produced pycnidia with predominantly $\alpha$-conidia and some with predominantly $\beta$-conidia or those with both the conidia types. They concluded that the Diaporthe isolates that produced predominantly $\beta$-conidia were similar to $D$. helianthi, as described in Yugoslavia. However, they were not able to resolve inconsistencies in the description of the Diaporthe isolates found in Ohio in comparison with those from Yugoslavia (Mihaljčević et al. 1985), particularly for those that produced predominantly $\alpha$-conidia. In our study, $D$. helianthi isolates produced white, floccose, and dense mycelia, dark-brown colored, on PDA; size of $\beta$-conidia (20 to 35 by 0.5 to $2.7 \mu \mathrm{m})$ was consistent with Gulya et al. (1997). In contrast, D. gulyae appeared flat in the center of the PDA plate and irregularly fluffy near the margin, with few aerial hyphae, and the size of $\alpha$-conidia ( 6.5 to 8.5 by 2.5 to $3.5 \mu \mathrm{m}$ ) was fairly consistent with Thompson et al. (2011). We did not observe $\beta$-conidia in D. gulyae. Additionally, D. gulyae caused leaf wilting, necrosis, and lodging in our aggressiveness study; these matched the symptoms described by Herr et al. (1983) but not those described by Mihaljčević et al. (1985) for D. helianthi. Comparison of the biological differences among Diaporthe isolates described by the previous researchers and in our study suggests that the two Diaporthe spp. were already present in the United States at low levels but the ability to distinguish them prior to molecular techniques did not exist.

The present study does suggest that $D$. helianthi was more prevalent than D. gulyae in the Northern Great Plains, and that they were not distributed in equal amounts across years or states. State and year variation between occurrences of Diaporthe spp. is likely a result of differences in sampling strategies as opposed to actual distribution of the two species. For instance, in 2010, sampling of stalks was based on the appearance of any stem disease and associated symptoms such as wilting, lodging, and plant death. In 2011 and 2012, sunflower stalks were sampled from fields heavily infected by Phomopsis stem canker. In these fields, D. helianthi was most frequently identified, which may suggest that $D$. helianthi may
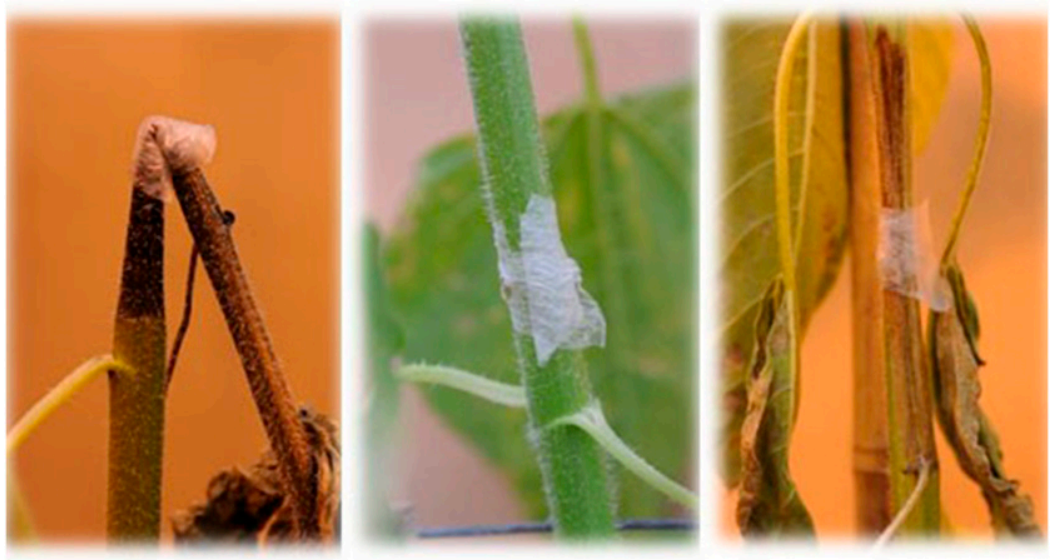

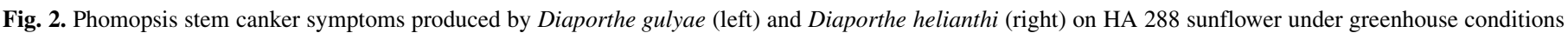

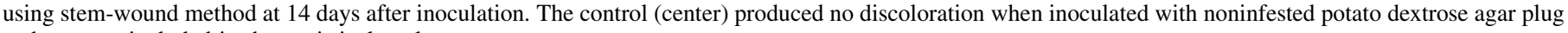
and was not included in the statistical analyses. 
be more of an economic concern for sunflower production in the Northern Great Plains than D. gulyae. However, year-to-year variation between species occurrence has been documented previously in pathogens such as Fusarium spp., and this was attributed to inoculum source and overwintering structures (Backhouse and Burgess 2002). For Diaporthe spp., although the perithecium is known to survive in debris for 5 years (Herr et al. 1983), there are no studies evaluating the influence of environmental conditions and survival of perithecia on the ability of the fungus to develop and persist as a pathogen. Although it is likely that environmental conditions or survival of perithecia may have an influence on the distribution of the two Diaporthe spp. in the Northern Great Plains, this was beyond the scope of our study.

This study is the first to compare the relative overall aggressiveness of the two Diaporthe spp., and results suggest that, although both are aggressive pathogens, D. gulyae was capable of causing necrosis, lodging, and plant death at a faster rate than $D$. helianthi. Similarly, isolates of D. gulyae and D. helianthi varied significantly in their aggressiveness within the two Diaporthe spp. D. helianthi produces toxins, including phomozin, which can result in premature leaf senescence, plant wilting, and lodging (Masirevic and Gulya 1992). Although there are no studies characterizing toxins produced by $D$. gulyae, the involvement of a toxin in the disease may explain these differences in terms of the varying aggressiveness between the two species and their individual isolates at specific times; for instance, 3 days after inoculation for $D$. gulyae and 10 days after inoculation for $D$. helianthi. Given that both Diaporthe spp. are present in the United States, knowledge of the relative aggressiveness of the two Diaporthe spp. may have important implications for the success of future breeding efforts and resistance deployment.

Prior to the reemergence of Phomopsis stem canker in 2010, breeding for resistance to the disease in the United States was likely not possible in natural field environments. Since then, public and private breeding programs have experienced natural Phomopsis stem canker epidemics and are actively screening germplasm for resistance. Sunflower lines resistant to $D$. helianthi were recently identified under natural disease pressure in field conditions (Talukder et al. 2014) but it is unclear whether the resistance in those lines is also conferred to D. gulyae. Breeders in the private sector are actively culling very susceptible germplasm when nurseries are affected by Phomopsis stem canker but rarely attempt to have the Diaporthe spp. inciting the disease identified. Given that $D$. gulyae and D. helianthi are both aggressive and present, it is very important to incorporate resistance that is effective against both pathogens. Although screening and culling efforts due to Phomopsis stem canker is an important first step to managing this disease, active incorporation of resistance effective against both pathogens is critical for future disease management.

This study was initiated in response to an increase in incidence, severity, and reports of yield losses to Phomopsis stem canker in the Northern Great Plains. Changes in the Diaporthe populations in the United States may have contributed to this recent emergence of the disease but our results suggest that it is more likely that an increase in disease is a result of other factors, and that the simultaneous identification of D. gulyae is circumstantial. The increase in Phomopsis stem canker could be partially explained by an increased production of sunflower on no-till and minimumtillage field ground, which could contribute to an increase in inoculum (Kandel 2012), or breeding in the absence of disease, which can inadvertently generate very susceptible hybrids. Additionally, some of the reported increases in Phomopsis stem canker incidence may be due to an increased ability among agronomists to accurately distinguish the disease from other common stem diseases, such as Phoma black stem (caused by Phoma macdonaldii Boerema) (Kandel 2012).

Although it is unclear which factors have facilitated the reemergence of Phomopsis stem canker as a major yield-limiting disease in the United States, the potential impact on sunflower production cannot be overstated. The incidence of Phomopsis stem canker across the U.S. Northern Great Plains remains approximately 10-fold higher than a decade ago. Yield losses due to Phomopsis stem canker have reached $50 \%$ in in noninoculated and nonirrigated research trials (Gilley et al. 2015; Mathew et al. 2015) and are thought to have been equally high in severely infected commercial fields. The presence of Phomopsis stem canker was recently determined to be a one of the most significant causes of genotype-environment variation in an ongoing study to understand sunflower crop testing environments; a notable find given the wide geography of the study and numerous yield-limiting factors affecting sunflower (B. Hulke, personal communication). International movement of sunflower seed could be influenced by the emergence of this disease, because $D$. helianthi is a quarantined pathogen in most countries but $D$. gulyae is not. The abrupt reemergence of Phomopsis stem canker is a new yield-limiting threat to sunflower growers in the United States, and an equally fast response by pathologists and breeders to develop and deploy management tools is needed to manage this disease.

\section{ACKNOWLEDGMENTS}

This research was supported by the National Sunflower Association (Mandan, ND). We thank P. Esker and J. LeBoldus for statistical advice; B. Nelson and T. Helms for providing helpful suggestions during revision of the manuscript; and E. Heitkamp, S. Choi, A. Streifel, C. Steffen, M. Ramsett, E. Crane, M. Gilley, N. Balbyshev, B. Lyslo, C. Taylor, and S. Choi for their technical assistance.

\section{LITERATURE CITED}

Aćimović, M., and Štraser, N. 1982. Phomopsis sp.-novi parazit suncokreta (Phomopsis sp.-New parasite in sunflower). Zast. Bilja 33(2):117-158 (English summary).

Akaike, H. 1974. New look at statistical-model identification. IEEE Trans. Automat. Contr. 19:716-723.

Akritas, M. G. 1991. Limitations of the rank transform procedure: A study of repeated measures designs, Part I. J. Am. Stat. Assoc. 86:457-460.

Backhouse, D., and Burgess, L. W. 2002. Climatic analysis of the distribution of Fusarium graminearum, F. pseudograminearum and F. culmorum on cereals in Australia. Australas. Plant Pathol. 31:321-327.

Barnett, H. L., and Hunter, B. B. 1972. Illustrated Genera of Imperfect Fungi, 3rd ed. Burgess Publishing Co., Minneapolis, MN.

Brunner, E., Domhof, S., and Langer, F. 2002. Nonparametric Analysis of Longitudinal Data in Factorial Experiments. John Wiley and Sons, New York.

Carbone, I., and Kohn, L. M. 1999. A method for designing primer sets for speciation studies in filamentous ascomycetes. Mycologia 91:553-556.

Carré, M. A. 1993. Maladies du tournesol: le choix varié tal avanttout. Cultivar 332:46-51.

Darlu, P., and Lecointre, G. 2002. When does the incongruence length difference test fail? Mol. Biol. Evol. 19:432-437.

Dettman, J. R., Jacobson, D. J., and Taylor, J. W. 2003. A multilocus genealogical approach to phylogenetic species recognition in the model eukaryote Neurospora. Evolution 57:2703-2720.

Encheva, V., and Kiryakov, I. 2002. A method for evaluation of sunflower resistance to Diaporthe/Phomopsis helianthi Munt. Cvet. et al. Bulg. J. Agric. Sci. 8:219-222.

Farris, J. S., Kallersjo, M., Kluge, A. G., and Bult, C. 1994. Testing significance of congruence. Cladistics 10:315-320.

Felsenstein, J. 1985. Confidence limits on phylogenies: An approach using the bootstrap. Evolution 39:783-791.

Gilley, M., Harveson, R., Schaefer, J., Kirsch, M., Caroline, J., and Markell, S. 2015. Evaluation of fungicides for management of Phomopsis stem canker. In: 37th Annu. Sunflower Res. Forum. Fargo, ND. Natl. Sunflower Assoc., Mandan, ND.

Gulya, T. J., Rashid, K. Y., and Masirevic, S. M. 1997. Sunflower diseases. Pages 313-319 in: Sunflower Technology and Production. A. A. Schneiter, ed. American Society of Agronomy, Madison, WI.

Hajdu, F., Baumer, J. S., and Gulya, T. 1984. Occurrence of Phomopsis stem canker in Minnesota and North Dakota. Page 15 in: Proc. Sunflower Res. Workshop, Bismarck, ND.

Hall, T. A. 1999. BioEdit: A user-friendly biological sequence alignment editor and analysis program for Windows 95/98/NT. Nucleic Acids. Symp. Ser. 41:95-98. 
Herr, L. J., Lipps, P. E., and Watters, B. L. 1983. Diaporthe stem canker of sunflower. Plant Dis. 67:911-913.

Kandel, H. 2012. 2011 National Sunflower Association survey results. In: Proc. 34th Sunflower Res. Workshop, Fargo, ND. National Sunflower Association, USA.

Lanave, C., Preparata, G., Saccone, C., and Serio, G. 1984. A new method for calculating evolutionary substitution rates. J. Mol. Evol. 20:86-93.

Laville, J. 1986. Cahier technique tournesol: maladie. CETIOM, Paris (in French)

Maddison, W. P., and Maddison, D. R. 2011. Mesquite: A modular system for evolutionary analysis. Version 2.75. Online publication. http://mesquiteproject.org

Masirevic, S., and Gulya, T. J. 1992. Sclerotinia and Phomopsis-Two devastating sunflower pathogens. Field Crops Res. 30:271-300.

Mathew, F., Grady, K., Byamukama, E., Hulke, B., and Markell, S. 2015. Assessing the impact of Phomopsis stem canker on sunflower yield. In: 37th Annu. Sunflower Res. Forum. Fargo, ND. Natl. Sunflower Assoc., Mandan, ND.

Mihaljčević, M., Muntañola-Cvetković, M., Vukojević, J., and Petrov, M. 1985. Source of infection of sunflower plants by Diaporthe helianthi in Yugoslavia. Phytopathol. Z. 113:334-342.

Miric, E. 2002. Pathological, morphological and molecular studies of a worldwide collection of the sunflower pathogens Phomopsis helianthi and Phoma macdonaldii. Ph.D. thesis, University of Queensland, Australia.

Muntañola-Cvetković, M., Mihaljčević, M., and Petrov, M. 1985. On the identity of the causative agent of a serious Phomopsis-Diaporthe disease in sunflower plants. Nova Hedwigia 34:417-435.

Nei, M., and Kumar, S. 2000. Molecular Evolution and Phylogenetics. Oxford University Press, New York.

Pariaud, B., Ravigné, V., Halkett, F., Goyeau, H., Carlier, J., and Lannou, C. 2009. Aggressiveness and its role in the adaptation of plant pathogens. Plant Pathol. 58:409-424.

Pentericci, S. 1988. La diffusione della Phomopsis nei paesi CEE evarieta resistenti. Sementi Elette 41:38-39.

Posada, D., and Crandall, K. A. 1998. Modeltest: Testing the model of DNA substitution. Bioinformatics 14:817-818.

Rambaut, A. 2009. FigTree v1.3.1: Tree figure drawing tool. Online publication. http://tree.bio.ed.ac.uk/software/figtree/

Rambaut, A., and Drummond, A. J. 2007. Tracer v1.4: MCMC trace analyses tool. Online publication. http://beast.bio.ed.ac.uk/Tracer

Rekab, D., Del Sorbo, G., Reggio, C., Zoina, A., and Firrao, G. 2004. Polymorphisms in nuclear rDNA and mtDNA reveal the polyphyletic nature of isolates of Phomopsis pathogenic to sunflower and a tight monophyletic clade of defined geographic origin. Mycol. Res. 108:393-402.
Ronquist, F., and Huelsenbeck, J. P. 2003. MrBayes 3: Bayesian phylogenetic inference under mixed models. Bioinformatics 19:1572-1574.

Says-Lesage, V., Roeckel-Drevet, P., Viguié, A., Tourvielle, J., Nicolas, P., and Tourvieille de Labrouhe, D. 2002. Molecular variability within Diaporthe/ Phomopsis helianthi from France. Phytopathology 92:308-313.

Shah, D. A., and Madden, L. V. 2004. Nonparametric analysis of ordinal data in designed factorial experiments. Phytopathology 94:33-43.

Swofford, D. L. 2002. Phylogenetic Analysis Using Parsimony (*and other methods), Version 4.0b10. Sinauer Associates, Sunderland, MA.

Talukder, Z. I., Hulke, B. S., Marek, L. F., and Gulya, T. J. 2014. Sources of resistance to sunflower diseases in a global collection of domesticated USDA Plant Introductions. Crop Sci. 54:694-705.

Tamura, K., Peterson, D., Peterson, N., Stecher, G., Nei, M., and Kumar, S. 2011. MEGA5: Molecular evolutionary genetics analysis using maximum likelihood, evolutionary distance and maximum parsimony methods. Mol. Biol. Evol. 28:2731-2739.

Thompson, J. D., Gibson, T. J., Plewniak, F., Jeanmougin, F., and Higgins, D. G. 1997. The CLUSTAL_X windows interface: Flexible strategies for multiple sequence alignment aided by quality analysis tools. Nucleic Acids Res. 25:4876-4882.

Thompson, S. M., Tan, Y. P., Young, A. J., Neate, S. M., Aitken, E. A. B., and Shivas, R. G. 2011. Stem cankers on sunflower (Helianthus annuus) in Australia reveal a complex of pathogenic Diaporthe (Phomopsis) species. Persoonia 27:80-89.

van Rensburg, J. C. J., Lamprecht, S. C., Groenewald, J. Z., Castlebury, L. A., and Crous, P. W. 2006. Characterization of Phomopsis spp. associated with die-back of rooibos (Aspalathus linearis) in South Africa. Stud. Mycol. 55: 65-74.

White, T. J., Bruns, T., Lee, S., and Taylor, J. 1990. Amplification and direct sequencing of fungal ribosomal RNA genes for phylogenetics. Pages 315-322 in: PCR Protocols: A Guide to Methods and Applications. M. A. Innis, D. H. Gelfand, J. J. Sninsky, and T. J. White, eds. Academic Press, San Diego, CA.

Wilcox, T. P., Zwickl, D. J., Heath, T. A., and Hillis, D. M. 2002. Phylogenetic relationships of the dwarf boas and a comparison of Bayesian and bootstrap measures of phylogenetic support. Mol. Phylogenet. Evol. 25:361-371.

Yang, S. M., Berry, R. W., Luttrell, L. E. S., and Vongkaysone, T. 1984. A new sunflower disease in Texas caused by Diaporthe helianthi. Plant Dis. 68: 254-255.

Yang, Z. 1994. Maximum likelihood phylogenetic estimation from DNA sequences with variable rates over sites: Approximate methods. J. Mol. Evol. 39:306-314. 